\title{
FIBRINA RICA EN PLAQUETAS UTILIZADA PARA PRESERVACIÓN DE REBORDE POST EXODONCIA: REPORTE DE CASO
}

\author{
FIBRIN PLATELET RICH IN USED FOR PRESERVATION OF FENCE POST \\ EXTRACTION: CASE REPORT
}

\author{
H. Dora Cámara, Cabello ${ }^{1 a, b}$
}

\section{RESUMEN}

La fibrina rica en plaquetas es un concentrado plaquetario de segunda generación, del cual podemos obtener un coágulo y/o una membrana con gran cantidad de factores de crecimiento, leucocitos y citoquinas, esta se consigue activando la cadena de coagulación mediante la centrifugación de sangre autóloga. En este protocolo no se manipula químicamente la sangre, lo que la convierte en una técnica accesible y sencilla para ser usada en la práctica clínica diaria. El presente caso describe la preservación de reborde post exodoncia del remanente radicular de la pieza 1.5. mediante exodoncia atraumática y la utilización de la fibrina rica en plaquetas obtenida con el protocolo de Choukroun como biomaterial de regeneración. El coágulo de fibrina fue dividido en dos partes, una parte como material de relleno autólogo (osteoinductor, osteoconductor) y otra como membrana autóloga para evitar el colapso del alveolo. A la evaluación clínica y radiográfica de seguimiento (1 mes y 12 meses), se evidencia la regeneración de la zona intervenida y la favorable evolución clínica.

Palabras clave: Alveolo dental; fibrina; regeneración ósea; plaquetas. (Fuente: DeCS)

\section{ABSTRACT}

The platelet-rich fibrin is a platelet concentrate of second generation, from which we can get a clot or a membrane with large number of growth factors, leukocytes and Cytokines, this is achieved by activating the chain through coagulation the centrifugation of autologous blood. In this Protocol not manipulated chemically blood, making it an accessible and simple technique to be used in daily clinical practice. This case describes the preservation of post extraction of the root remnant of the 1.5 piece flange. through Atraumatic extraction and the use of platelet-rich fibrin obtained Choukroun as biomaterial of regeneration Protocol. Fibrin clot was divided into two parts, a part as filler material autologous (osteoinductive, osteoconductive) and other such as autologous membrane to prevent the collapse of the alveoli. The clinical and radiographic evaluation of follow-up (1 month and 12 months), there is evidence of the regeneration of the area intervened and favorable clinical evolution

Key words: Tooth socket; fibrin; bone regeneration; platelets. (Source: MeSH NLM) 


\section{INTRODUCCIÓN}

La fibrina rica en plaquetas de Choukroun (PRF) es una segunda generación de concentrados plaquetarios que consta de un conjunto íntimo de citoquinas y glicoproteínas estructurales atrapadas dentro de una red de fibrina lentamente polimerizada(1).

Actualmente, con un mayor conocimiento acerca de los factores de crecimiento es cuando empiezan a aparecer estudios esperanzadores en el campo de la regeneración ósea, basados en promover la diferenciación, migración y proliferación de las células involucradas en la regeneración.

En el presente reporte se utilizó la fibrina rica en plaquetas (PRF- Platelet rich of fibrin Choukroun's) tanto como material de relleno óseo autólogo (osteoinductor, osteoconductor) y como membrana autóloga para cubrir dicho relleno y evitar el colapso del alvéolo.

El objetivo del reporte del caso es demostrar la fácil aplicación del PRF, como biomaterial autólogo en ingeniería de tejidos, con un bajo costo, para brindar una alternativa de solución a aquellos pacientes que no cuentan con los recursos económicos suficientes para someterse a un proceso de regeneración convencional.

Los resultados de estudios como el de Lekovic et al. muestran menos pérdida de altura ósea, mayor relleno óseo del alvéolo y menos reabsorción horizontal al usar membranas que al no usarlas(2).

Sus ventajas sobre el plasma rico en plaquetas (PRP) incluyen la facilidad de su preparación, ya que a diferencia del PRP, esta técnica no requiere de anticoagulante ni trombina bovina (ni ningún otro agente gelificante) ${ }^{(3)}$.

Numerosos materiales biocompatibles han sido usados en alvéolos post-extracción como material de relleno. El uso de estos materiales de relleno nos ayuda a prevenir el colapso de las paredes del alvéolo tras la extracción de un diente, evitando perder tejidos duros y blandos, reduciendo el número de procedimientos quirúrgicos y proporcionando resultados óptimos y estéticos de alta

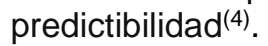

Según Wang, un promedio de un $40 \%$ a $60 \%$ de la altura y ancho original de la cresta puede llegar a perderse en los primeros 2 años post-exodoncia, siendo mayor en mandíbula $(0,4 \mathrm{~mm} / \mathrm{año})$ que en maxila $(0,1 \mathrm{~mm} / \mathrm{año})$, lo cual puede perjudicar el resultado final de una rehabilitación en ese sitio(5). Por ello es importante seguir en la búsqueda del mejor biomaterial para preservar el reborde, no solo como relleno, sino con una membrana que evite el colapso del alvéolo.

El uso de una membrana elimina el problema de que migren las partículas del injerto fuera del defecto del alvéolo, mientras previene la invaginación también del tejido blando y epitelial dentro del alvéolo de cicatrización ${ }^{(6)}$

\section{DESCRIPCIÓN DEL CASO}

\section{Información de paciente}

Paciente de 21 años de edad, de sexo femenino, de ocupación chef, sin antecedentes patológicos, acude a la Clínica Estomatológica de la Segunda Especialidad de Periodoncia e Implantología de la Universidad Católica de Santa María (Arequipa, Perú), con un proceso inflamatorio agudo en fondo de surco a nivel de la pieza 1.6, con dolor, sin lesión aparente en piezas dentales y con ausencia clínica de la pieza 1.5.

\section{Hallazgos Clínicos}

Al examen radiográfico se evidencia remanente radicular de la pieza 1,5 , con una imagen radiolúcida compatible con un proceso periapical (Figura 1).
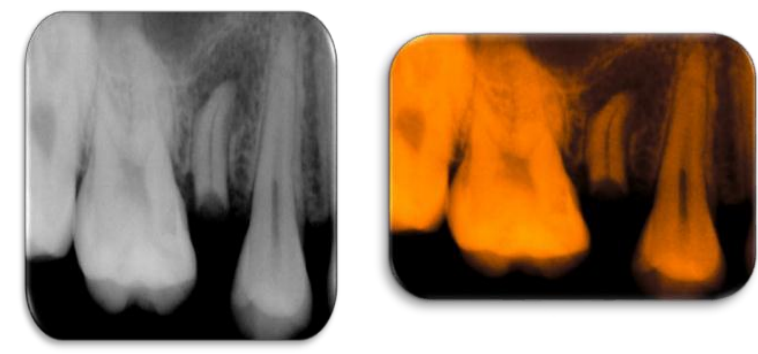

Figura 1. Radiografía y RVG de diagnóstico. 
La paciente fue medicada por vía oral con clindamicina, 300mg cada 6 horas por 5 días. $\mathrm{Al}$ tercer día del tratamiento antibiótico, sin antecedentes de ingesta de aspirina $u$ otros medicamentos que puedan interferir con la coagulación.

Durante las 2 semanas anteriores y con la firma del consentimiento informado se procedió a realizar la extracción del remanente radicular a colgajo con preservación de reborde alveolar, utilizando PRF, una parte como relleno alveolar y la otra como membrana.

\section{Preparación de Fibrina Rica en Plaquetas (PRF)}

Inmediatamente, antes del procedimiento quirúrgico se procedió a la extracción de sangre $(10 \mathrm{ml})$ de una vena de la región antecubital con una jeringa descartable de $10 \mathrm{ml}$ (Figura 2) y se depositó en un tubo de vidrio con tapa, previamente autoclavado y sin ningún tipo de aditivo ya que la sangre al entrar en contacto con el vidrio activa la cascada de coagulación. El recojo de la sangre se realizó de manera rápida para evitar la coagulación antes de la centrifugación. Se colocó el tubo en la centrífuga por $10 \mathrm{~min}$ a $3000 \mathrm{rpm}$.

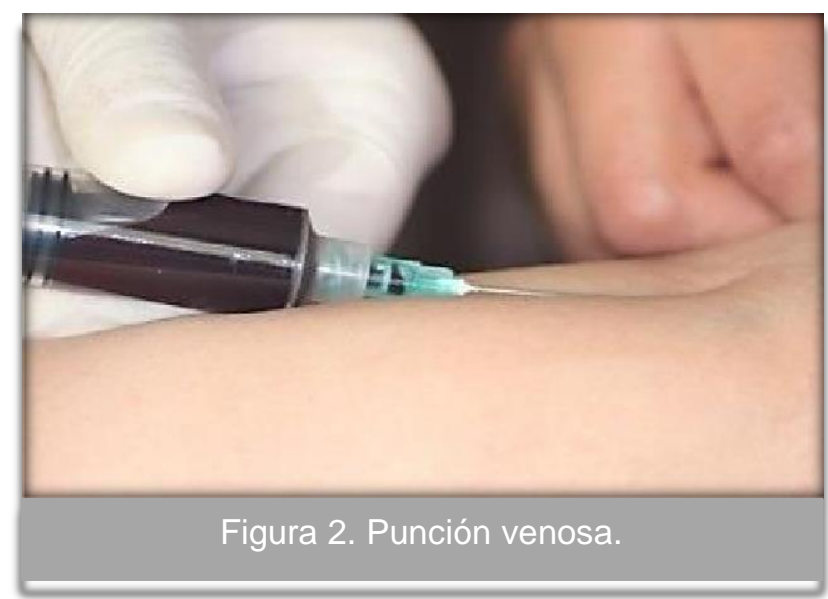

Al mismo tiempo de la centrifugación de la sangre, se realizó la extracción del remanente radicular con la técnica atraumática mediante colgajo mucoperióstico e incisión crestal. Culminado el tiempo de centrifugado se observa la separación de los componentes de la sangre (Figura 3), fracción 1, correspondiente al Plasma Pobre en Plaquetas (PPP). Se procedió a retirar el coágulo de fibrina correspondiente a la fracción 2 (Figura 4). Se separa el coágulo de fibrina de la serie roja (Red Blood Cells - RBC), fracción 4, con unas tijeras a manera de un pell de manera suave para conservar la mayor cantidad de factores de crecimiento en la fibrina (Figura 5) y se coloca en una placa petri previamente autoclavada.

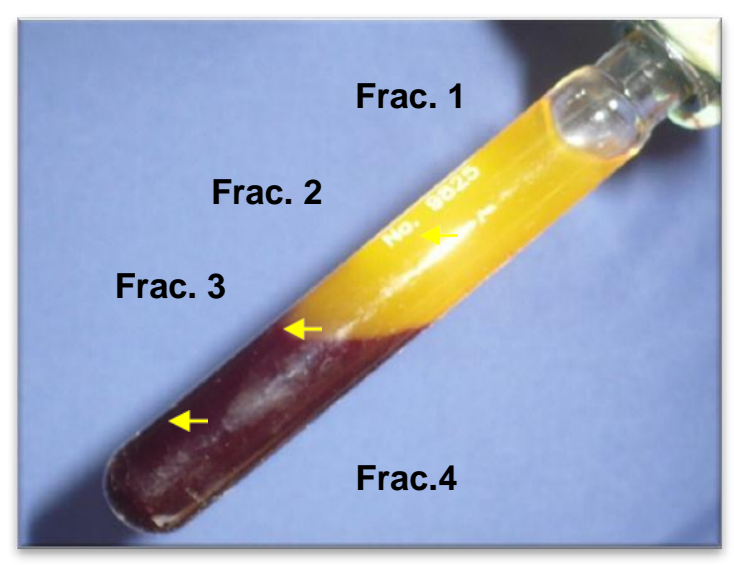

Figura 3. Separación de componentes
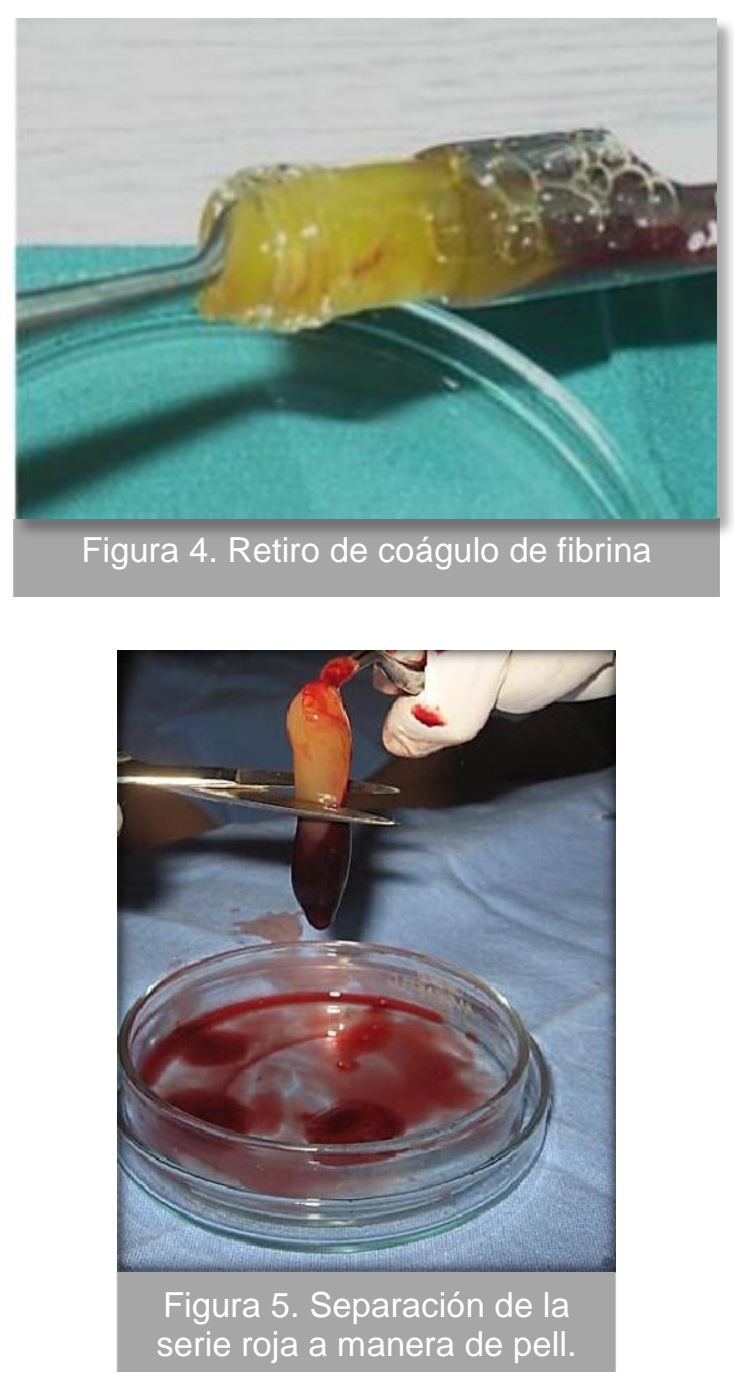
Obtenido el coágulo de fibrina se divide el mismo en dos partes iguales, una destinada para relleno intraalveolar (Figura 6) y la otra colocada en una gasa estéril con la finalidad de eliminar el exudado para la posterior conformación de la membrana mediante presión digital en una placa Petri (Figura 7), para colocar la membrana encima del alveolo y así evitar el colapso del mismo (Figura 8). Observamos en la figura 9 la membrana ya conformada.
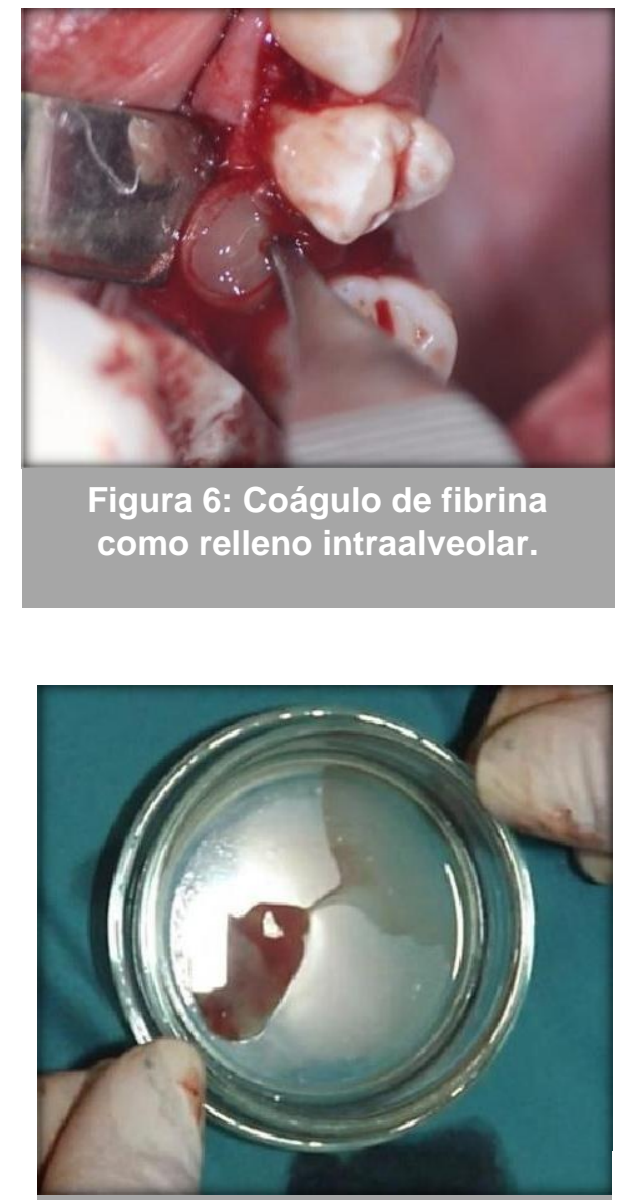

Figura 7: Presión digital en la placa Petri para conformación de la membrana.

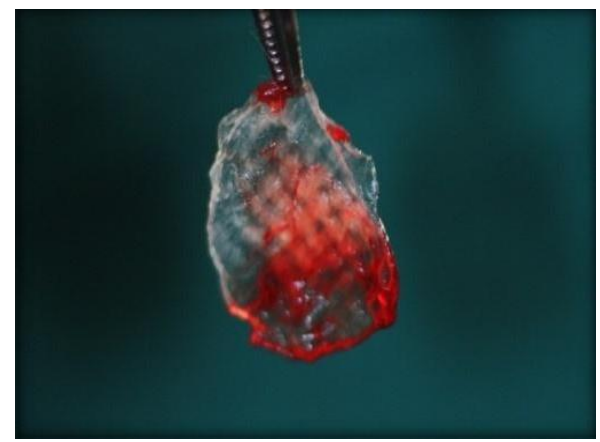

Figura 9: Membrana de fibrina autóloga.
Una vez colocado el relleno y estabilizada la membrana, se realizó la sutura (seda negra 4.0) con puntos simples. Se prescribe enjuague con clorhexidina al $0,12 \%, 15 \mathrm{ml}$ mañana y noche durante 7 días e ibuprofeno $400 \mathrm{mg}$ condicionante al dolor.

Los controles fueron realizados radiográfica y clínicamente el mismo día de la cirugía (Figura 10), al mes (Figura 11) y a los 12 meses (Figura 12).

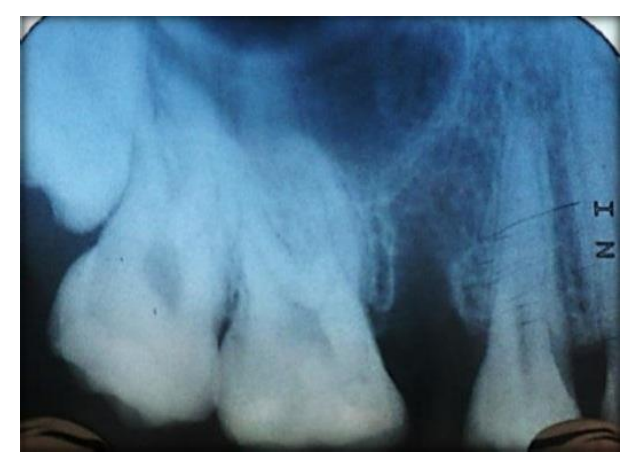

Figura 10. Radiografía a las 2 horas de la cirugía
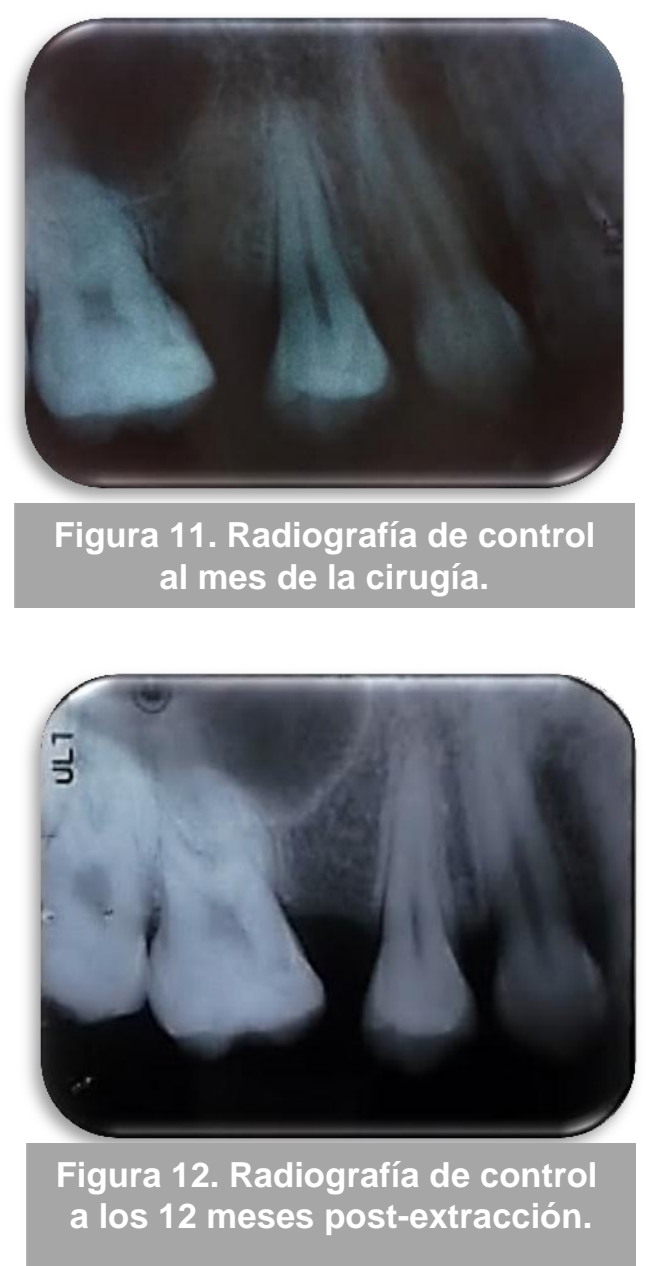


\section{SEGUIMIENTO CLÍNICO}

Dentro de los resultados obtenidos, se observó clínicamente evolución satisfactoria del proceso de cicatrización, con notable disminución del edema y dolor postquirúrgico. Por medio de radiografías se puede observar la radio opacidad y la disminución de la interfase del coágulo colocado en el proceso alveolar (Figura 13).

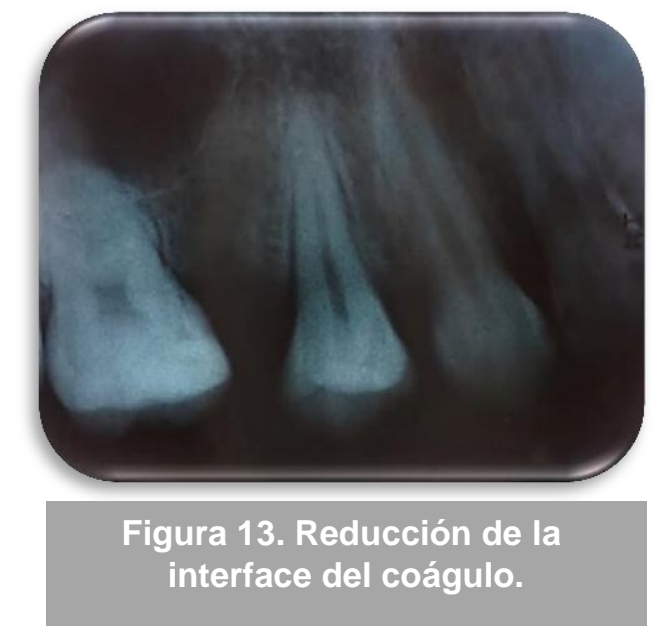

\section{DISCUSIÓN}

Es importante reconocer que este procedimiento disminuye la necesidad de intervenciones quirúrgicas posteriores, como regularización de rebordes y otras regeneraciones, disminuyendo también la frecuencia de complicaciones y el costo, en comparación con membranas de colágeno o de ácido láctico reabsorbible.

Existen varios estudios sobre las membranas basadas en PRF, donde se han utilizado para cubrir el aumento de la cresta alveolar in vivo. Gassling et al. (7) han comparado el uso de la membrana de PRF con la membrana de colágeno Bio-Gide como andamiaje para la ingeniería de tejidos periósticos. Esta demostró ser superior al colágeno (Bio-Gide) como andamiaje para la proliferación celular perióstica en el humano. Membranas PRF también demuestran ser aptas para el cultivo in vitro de células del periostio para la ingeniería de tejido óseo.

Dentro de las principales ventajas y las razones por las cuales se utilizó PRF y no otros concentrados plaquetarios, como el PRP (plasma rico en plaquetas) son:

- Que no requiere ningún anticoagulante o agente gelificante.

- $\quad$ No se manipula químicamente la sangre(8).

- Esta forma natural del coágulo PRF tiene una densa y compleja arquitectura tridimensional(9).

- En este tipo de coágulo se concentran no sólo las plaquetas, sino también los leucocitos.

- Es menos riesgoso para los pacientes porque no los expone a agentes anticoagulantes derivados de animales.

Otro beneficio encontrado en comparación con los injertos aloplásticos o sintéticos, es que estos funcionan como material de relleno y no de regeneración para una futura colocación de implantes, a diferencia del PRF donde se observa una clara regeneración y no una reparación ${ }^{(10)}$.

Los leucocitos parecen influir fuertemente en la liberación de factores de crecimiento, en la regulación inmune, en las actividades antiinfecciosas y remodelación de la matriz durante la cicatrización (11).

Debido a su densa matriz de fibrina, la PRF tarda más en ser reabsorbida por el paciente, lo que resulta ser el más lento y sostenido mecanismo de liberación de las plaquetas y factores de crecimiento en el área de la herida en comparación con otras técnicas regenerativas (12). Por último, en virtud de que contiene leucocitos, la PRF puede ejercer un efecto antibacteriano en la herida y trabajar como una fuente abundante de factor de crecimiento endotelial vascular, que es un factor clave en la angiogénesis. En general, la PRF tiene física y atributos bioquímicos que la hacen atractiva para su aplicación en periodoncia, implantología, cirugía oral y en el proceso de la curación de heridas ${ }^{(13)}$.

Se ha descrito su utilización en alvéolos postextracción o postavulsión como único material para preservar el alvéolo, demostrando la formación de hueso tras 6 semanas sin signos de reabsorción ósea. Su uso aislado en alvéolos se recomienda cuando las paredes están intactas. Cuando una o más paredes están ausentes 0 dañadas, es recomendable usar L-PRF en combinación con sustitutos óseos, demostrando a su vez un excelente comportamiento como conector biológico entre las partículas óseas (14). 
Se concluye que la utilización del coágulo y de la membrana de fibrina autóloga en este reporte de caso comprueba que es el protocolo con más fácil preparación y manipulación a diferencia de otros preparados plaquetarios y que puede ser usado en la práctica clínica diaria como el mejor tratamiento de elección en odontología: incrementa la densidad ósea, mejora la calidad y cantidad de hueso en un menor tiempo, disminuye la sintomatología postoperatoria y reduce significativamente los costos para los pacientes.

El coágulo de fibrina se utilizó con dos propósitos: tanto como material de relleno autólogo y como membrana autóloga, y se logró evitar el colapso del alveolo. A la evaluación clínica se observó la favorable evolución del paciente sin dolor ni ningún otro signo de inflamación. Radiográficamente se evidenció la regeneración de la zona intervenida y la rápida disminución de la interfase del coágulo con el hueso circundante.

El potencial biotecnológico, tanto clínico como de sus aplicaciones del PRF, es revolucionario, sus aplicaciones son numerosas y requiere de nuevos estudios para entender más claramente sus mecanismos biológicos, particularmente sobre el papel de los leucocitos y para dominar la preparación de este concentrado plaquetario.

\section{Fuente de financiamiento:}

Autofinanciado.

\section{REFERENCIAS BIBLIOGRÁFICAS}

1. Meza J, Lecca M, Correa E, Ríos K. Fibrina rica en plaquetas y su aplicación en periodoncia: revisión de literatura. Rev Estomatol Herediana. 2014; 24 (4): 287 293.

2 Lekovic V, Kenney EB, Weinlaender M, Han T, Klokkevold $\mathrm{P}$, Nedic $\mathrm{M}$ et al. A Bone regenerative approach to alveolar ridge maintenance following tooth extraction. Report of 10 Cases. J Periodontology 1997; 68(6): 563-70
3. Toffler M, Toscano N, Holtzclaw D, Corso MD, Dohan Ehrenfest D. Introducing Choukroun's platelet rich fibrin (PRF) to the reconstructive surgery milieu. J Implant Adv Clin Dent. 2009; 1(6):21-30.

4. Ashman A. Ridge preservation: important buzzwords in dentistry. Gen Dent 2000; 48(3): 304-12.

5. Wang, KN. Socket augmentation: rationale and technique. Implant Dent 2004; 13 (4): 286-93.

6. Fowler EB, Breault LG, Rebitski G. Ridge preservation utilizing an acellular dermal allograft and demineralized freeze-dried bone allograft: Part I. A report of 2 cases. J Periodontology 2000; 71(8): 1353- 9.

7. Gassling V, Douglas T, Warnke PH, Acil Y, Wiltfang J, Becker ST. Platelet-rich fibrin membranes as scaffolds for periosteal tissue engineering. Clin Oral Implants Res 2010 May; 21(5): 543-9.

8. Dohan DM, Choukroun J, Diss a et al. Platelet-rich fibrin (PRF): a second-generation platelet concentrate. Part III: leukocyte activation: a new feature for platelet concentrates. Oral Surg Oral Med Oral Pathol Oral Radiol Endod 2006; 101 (): 51-55.

9. Dohan Ehrenfest DM, Del Corso M, Diss A, Mouhyi J, Charrier JP. Three-dimensional architecture and cell composition of a Choukrouns platelet-rich fibrin clot and membrane. J Periodontol 2010; 81: 546-555.

10. Ashman A. Post extraction ridge preservation using a synthetic alloplast. Implant Dent 2000; 9(2): 168-76.

11. Leigha R. Potential of platelet rich fibrin in regenerative periodontal therapy: literature review. Can J Dent Hyg. 2013; 47(1):33-7

12 Dohan DM, Choukroun J, Diss a et al. Platelet-rich fibrin (PRF): a second-generation platelet concentrate. Part II: platelet-related biologic features. Oral Surg Oral Med Oral Pathol Oral Radiol Endod 2006; 101: 45-50.

13. Dohan Ehrenfest DM, de Peppo GM, Doglioli P, Sammartino $G$. Slow release of growth factors and thrombospondin-1 in Choukroun_s platelet-rich fibrin (PRF): a gold standard to achieve for all surgical platelet concentrates technologies. Growth Factors 2009; 27(4): 63-69.

14. Salgado-Peralvo A, Salgado-García A, Arriba-Fuente L. Nuevas tendencias en regeneración tisular: fibrina rica en plaquetas y leucocitos. Revista Española de Cirugía Oral y Maxilofacial, ISSN: 1130-0558, Vol: 39, Issue: 2, Page: 91-98 Publication Year: 2017 